\title{
Rabies: the clinical features, management and prevention of the classic zoonosis
}

\author{
Authors: Mary J Warrell ${ }^{A}$ and David A Warrell ${ }^{B}$
}

The diagnosis of rabies encephalitis relies on awareness of the varied clinical features and eliciting a history of unusual contact with a mammal throughout the endemic area. The diagnosis is easily missed. Laboratory tests are not routine and only confirm clinical suspicion. Rabies infection carries a case fatality exceeding 99.9\%. Palliation is appropriate, except for previouslyvaccinated patients or those infected by American bats, for whom intensive care is probably indicated. However, as rabies vaccines are outstandingly effective, no one should die of dog-transmitted infection. Vaccines and rabies immunoglobulin are expensive and usually scarce in Asia and Africa. All travellers to dog rabies enzootic areas should be strongly encouraged to have pre-exposure immunisation before departure. There is no contraindication to vaccination but the cost can be prohibitive. Intradermal immunisation, using 0.1 $\mathrm{ml}$ and sharing vials of vaccine, is cheaper and is now permitted by UK regulations. Returning travellers may need post-exposure prophylaxis. Economical intradermal post-exposure vaccination is practicable and should be introduced into rural areas of Africa and Asia immediately. Eliminating rabies in dogs is now feasible and would dramatically reduce human mortality, if funds were made available. The high current economic burden of human prophylaxis would then be largely relieved.

Rabies virus causes fatal encephalomyelitis in humans. It is one of 12 species of the Lyssavirus genus. ${ }^{1}$ The other species, mainly of bats, are rabies-related lyssaviruses that may be equally pathogenic. ${ }^{2-4}$ Rabies infection should be entirely preventable. However, when effective treatment is unavailable, unaffordable, delayed or incomplete, virus inoculated into a bite wound can ascend intraneuronally to the brain ${ }^{5}$ resulting in fatal encephalomyelitis (Fig 1).

Authors: Ahonorary research associate, Oxford Vaccine Group, University of Oxford, Oxford, UK; Binternational director (Hans Sloane fellow), Royal College of Physicians, London, UK, and emeritus professor of tropical medicine, Nuffield Department of Clinical Medicine, University of Oxford, Oxford, UK

\section{Epidemiology}

Dogs, the main rabies reservoir species, usually infect by an unprovoked bite. Wild mammals such as foxes, raccoons, skunks and wolves are also reservoirs in certain countries and lyssavirus infection of bats has been detected everywhere it has been sought (Table 1). Canine rabies virus causes $99 \%$ of the human deaths. ${ }^{6}$ All mammals are susceptible to rabies and are potential vectors (able to transmit the virus) including cats, other domestic animals but rarely monkeys. ${ }^{7}$ Bites by rodents carry a very low risk.

\section{Clinical rabies encephalomyelitis}

Early recognition depends on eliciting a history of a bite or other contact with a possibly infected mammal, most commonly in dog rabies endemic areas of Asia, Africa or South America. There is a wide range of non-specific prodromal symptoms, so rabies patients have presented to rheumatologists, neurologists, psychiatrists, cardiologists, respiratory and acute medicine physicians, ear, nose and throat specialists, general and transplant surgeons ${ }^{8}$ and GPs. The main clinical features ${ }^{9,10}$ are listed in Box 1.

\section{Prognosis}

Without intensive care, unvaccinated victims of furious rabies encephalomyelitis die within a few days, but patients with paralytic rabies may survive for weeks.

Ten case reports of prolonged survival or recovery from rabies have been published. ${ }^{11,12}$ In all but one, one or more doses of vaccine had been received, post- or pre-exposure. Diagnoses were based on detection of very high neutralising antibody levels, or, rarely, by polymerase chain reaction (PCR) or antigen detection. Among the three recoveries, two had been vaccinated after a $\operatorname{dog}^{11}$ or bat ${ }^{13}$ bite, and one unvaccinated patient recovered from a bat infection. ${ }^{14}$ American bat rabies viruses may be less pathogenic in humans. All other survivors suffered severe neurological sequelae. ${ }^{12}$ No unvaccinated patient infected by a dog or other terrestrial mammal is known to have recovered from rabies encephalitis. Patients who recovered showed early development of neutralising antibody.

\section{Diagnosis}

Rapid diagnosis of rabies encephalomyelitis intra vitam is possible by PCR on saliva, cerebrospinal fluid, respiratory 


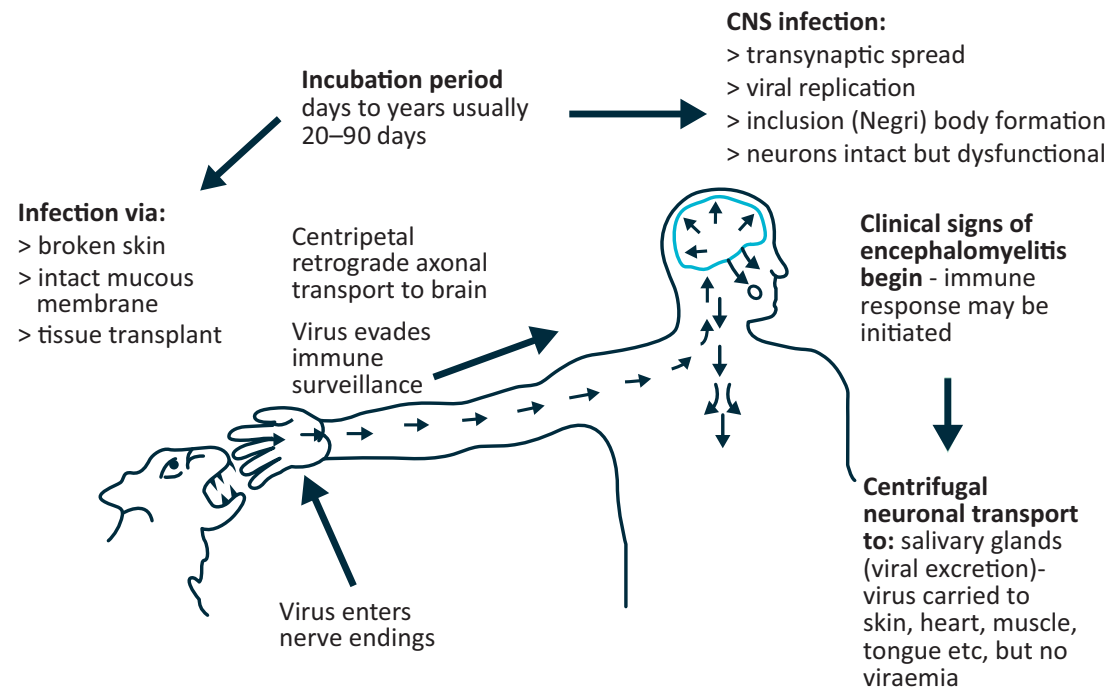

Fig 1. Rabies pathogenesis.

secretions, tears and skin biopsies and by immunofluorescent staining of skin sections. Daily samples should be tested until a diagnosis is confirmed. Virus isolation is ideal but takes days. Unvaccinated patients can be diagnosed by finding neutralising antibody. Contact the destination laboratory before taking samples.

\section{Management}

Partially-documented cases of human rabies survival, reported over the last 40 years, have provided hope that rabies encephalomyelitis might be treatable. However no specific treatment has proved effective. Rabies of canine origin remains $100 \%$ fatal in unvaccinated people. Patients should be admitted to hospital so that their agonising symptoms can be palliated with adequate doses of analgesic and sedative drugs..$^{15}$ Those contaminated by patient saliva should be given prophylaxis. Hospital staff or carers are vaccinated for reassurance. Intensive care may be appropriate in previously vaccinated patients, or those infected by an American bat virus, especially those presenting early with detectable rabies antibody.

\section{Key points}

Any mammal can transmit rabies but dog rabies virus causes $99 \%$ of human rabies deaths

Only pre-exposure immunisation followed by post-exposure boosting has provided complete protection against disease

Only one unvaccinated person and two partially-vaccinated ones have recovered from rabies encephalomyelitis for which there is no specific antiviral treatment

Intensive care is appropriate in very few cases, only, perhaps, those previously immunised and those infected with American bat rabies virus, which may be less pathogenic in humans

KEYWORDS: rabies vaccine, lyssavirus, bat, dog, encephalitis

\section{Prophylaxis}

Rabies vaccine is usually given after exposure to a possibly rabid mammal, but it is more effective if used beforehand. The combination of pre-exposure immunisation followed by postexposure boosting has proved $100 \%$ effective.

\section{Pre-exposure vaccination}

Pre-exposure vaccination is recommended for anyone at risk of contact with a rabid domestic or wild mammal. Contact with a bat anywhere in the world constitutes a possible risk. Travellers should avoid dogs, cats and wild mammals in rabies enzootic areas. A pre-exposure vaccine course is required only once in a lifetime. It is strongly recommended for travellers to, and residents of, countries with dog rabies, ${ }^{16}$ and for those at risk through occupation or leisure activities. To reduce the cost, this vaccine can be injected ID. The pre-exposure vaccine regimen is three doses: on days 0,7 and 28, either one vial IM or $0.1 \mathrm{ml}$ ID in the deltoid area (Table 2). ${ }^{6}$ The timing of the final dose can be delayed or advanced to day 21 . The vaccine must be given IM if immunosuppression is suspected, including by chloroquine medication. The UK regulations permit ID injection by suitably qualified and experienced healthcare professionals with warnings about the prescriber's responsibility and the risk of contamination of vials. ${ }^{17}$

If there is insufficient time for a full vaccine course before travel, give one or two doses. Having had any vaccine previously is better than none if you are exposed to rabies. The course can be completed later. Booster doses of pre-exposure vaccine are not normally required for travellers if they will have access to vaccine for post-exposure boosting if needed. If vaccine will not be rapidly available, a single booster dose after 5 years is advisable. ${ }^{18}$ Booster doses are recommended for people at occupational or high risk of exposure. ${ }^{6,19}$

\section{Post-exposure vaccination}

Post-exposure treatment is given if a possibly rabid mammal bites or scratches, or licks a mucous membrane. Wound cleaning, rabies vaccination and rabies immune globulin 
Table 1. Principal rabies reservoir mammal species.

\begin{tabular}{|c|c|c|}
\hline Continent & Mammal species & Region \\
\hline \multirow[t]{3}{*}{ Africa } & Domestic dog & Widespread dominant reservoir \\
\hline & Jackal, mongoose & Southern Africa \\
\hline & Frugivorous and insectivorous bats (Duvenhage virus ${ }^{a}$ ) & \\
\hline \multirow[t]{3}{*}{ Asia } & Domestic dog & Widespread dominant reservoir \\
\hline & Wolf & Middle East \\
\hline & Chinese ferret badger & China and Taiwan \\
\hline \multirow[t]{6}{*}{ North America } & Arctic fox & Alaska and north-west Canada \\
\hline & Red fox & Western Canada and north-east USA \\
\hline & Gray fox & Texas and Arizona \\
\hline & Striped skunk & Texas, central USA and California \\
\hline & Raccoon & Eastern USA and south-east Canada \\
\hline & Insectivorous bats & Very widespread \\
\hline \multirow[t]{4}{*}{$\begin{array}{l}\text { Central and } \\
\text { South America }\end{array}$} & Vampire bats & $\begin{array}{l}\text { Mexico, Trinidad, Tobago, Isla de Margarita and Northern } \\
\text { South America }\end{array}$ \\
\hline & Frugivorous and insectivorous bats & South America \\
\hline & Mongoose & Puerto Rico, Grenada, Cuba and Dominican Republic \\
\hline & Domestic dog & Mexico and parts of Central and South America \\
\hline \multirow[t]{2}{*}{ Australia } & Frugivorous and insectivorous bats & Eastern coastal region \\
\hline & (Australian bat lyssavirus $^{a}$ ) & \\
\hline \multirow[t]{6}{*}{ Europe } & Red fox & Eastern Europe, Russian Federation. \\
\hline & Arctic fox & Northern Russia \\
\hline & Raccoon dog & Eastern Europe \\
\hline & Wolf & Eastern Europe and Russian Federation. \\
\hline & Domestic dog & Turkey and Russian Federation \\
\hline & Insectivorous bats (European bat lyssaviruses ${ }^{a}$ ) & Widespread \\
\hline \multicolumn{2}{|c|}{$\begin{array}{l}\text { Some countries where no rabies has been reported in terrestrial } \\
\text { mammals or bats }\end{array}$} & $\begin{array}{l}\text { Iceland, Italy, some Mediterranean, Caribbean and other } \\
\text { islands, Singapore, Sabah, Sarawak, New Guinea, New } \\
\text { Zealand, Oceania, Hong Kong islands, Japan and Antarctica }\end{array}$ \\
\hline
\end{tabular}

(RIG) are urgently required. However, it is never too late to start treatment. There is no contraindication to post-exposure therapy. Wash the wound thoroughly with soap or detergent and water and apply povidone iodine. For those previously immunised with at least three doses of vaccine, RIG treatment is not necessary but post-exposure boosting is essential using two doses on days 0 and 3 (Table 2). The primary postexposure vaccine regimen in the UK is the IM ('Essen') regimen of five doses on days $0,3,7,14$ and 28 into the deltoid (Table 2)..$^{18}$ Outside the UK, other IM and ID post-exposure regimens are used. High costs and limited supplies of vaccine result in many preventable deaths. Many lives could be saved if safe, economical ID vaccine regimens were accepted globally. ${ }^{18}$

Passive immunisation neutralises virus in the wound, providing crucial protection during the 7-10 days before vaccine induced immunity appears. RIG is not needed if vaccine had been started $>7$ days previously. Local analgesia is advisable before injection. A dose of human RIG, $20 \mathrm{U} / \mathrm{kg}$
Table 2. Rabies prophylaxis recommended in the UK.

\begin{tabular}{|c|c|c|}
\hline Vaccine $^{a}$ regimen & Days of injection & Visits \\
\hline \multicolumn{3}{|l|}{ Pre-exposure } \\
\hline IM & $0,7,21-28$ & \multirow[t]{2}{*}{3} \\
\hline ID $\left(\left.0.1 \mathrm{~m}\right|^{\mathrm{b}}\right)$ & $0,7,21-28$ & \\
\hline \multicolumn{3}{|l|}{ Primary post-exposure: } \\
\hline RIG & 0 & \\
\hline IM vaccine & $0,3,7,14,28$ & 5 \\
\hline $\begin{array}{l}\text { If previously immunised - } \\
\text { post-exposure boosting IM }\end{array}$ & 0,3 & 2 \\
\hline \multicolumn{3}{|c|}{$\begin{array}{l}\text { aHuman diploid cell vaccine (Rabies vaccine, Imovax TM: Sanofi Pasteur) IM } \\
\text { dose is } 1 \mathrm{ml} \text {. Purified chick embryo cell vaccine (Rabipur/Rabavert TM, Novartis) } \\
\text { IM dose is } 1 \mathrm{ml} \text {. Purified Vero cell vaccine (Verorab }{ }^{\mathrm{TM}} \text {; Sanofi Pasteur) IM dose } \\
\text { is } 0.5 \mathrm{ml} \text { (not licensed in UK or North America). }\end{array}$} \\
\hline \multicolumn{3}{|c|}{$\begin{array}{l}\text { bReduce cost, share a vaccine vial between several people on the same day, with } \\
\text { separate needles and strict aseptic precautions. RIG = rabies immune globulin. }\end{array}$} \\
\hline
\end{tabular}




\section{Box 1. Clinical features of rabies encephalitis.}

\section{Prodrome}

> Fever and itching, pain or paraesthesiae near the site of the healed bite wound

\section{Furious rabies}

> Hydrophobia: violent, jerky inspiratory muscle spasms and hyperextension, associated with indescribable terror, provoked by attempts to drink (or sight, sound or mention of water) or a draft of air ('aerophobia'); Pathophysiology: brainstem and limbic system affected: exaggeration of airway protective reflexes, loss of inhibition of inspiratory reflexes, reinforced by conditioning

> Phases of arousal (hallucinations, fear, aggression) and lucid intervals

$>$ Cranial nerve lesions especially III,VII, VIII

> Fasciculations and myoclonus

> Autonomic stimulation: hypersalivation, lacrimation, sweating, loss of temperature control, labile blood pressure and priapism

$>$ Cardiac tachyarrhythmias

$>$ Coma

$>$ Paralysis

Axonal neuropathy

\section{Complications}

> Cardiac: arrhythmias, hypotension, myocarditis and cardiac failure

> Respiratory: asphyxiation, pneumonia, pneumothorax, inspiratory spasms, periodic breathing- cluster breathing, Cheyne-Stokes and other respiratory arrhythmias, ARDS and respiratory failure

> Neurological/endocrinological: convulsions, hypo-/ hyperpyrexia, diabetes insipidus, inappropriate ADH secretion and cerebral oedema

> Gastroenterological: bleeding, Mallory-Weiss tears and stress ulceration

\section{Paralytic rabies}

$>$ Ascending paralysis and loss of tendon reflexes

$>$ Sensory symptoms

> Sphincter dysfunction

$>$ Fever, sweating, gooseflesh and fasciculation

$>$ Bulbar/respiratory paralysis

$\mathrm{ADH}=$ antidiuretic hormone; $\mathrm{ARDS}=$ acute respiratory distress syndrome.

body weight, should be infiltrated into and around the wound. If this is impossible, for example in a finger, give the rest IM, preferably into the anterolateral thigh, but not the gluteal region. There is a global shortage of RIG. It is not available in several countries and many rural areas.

\section{Solving the problem of human rabies?}

Dog rabies can be eliminated by mass vaccination and contraception for stray dogs. This is the best and most economical way of preventing human rabies in the long term. ${ }^{20}$

\section{References}

1 Calisher $\mathrm{CH}$, Ellison JA. The other rabies viruses: The emergence and importance of lyssaviruses from bats and other vertebrates. Travel Med Infect Dis 2012;10:69-79.

2 Nathwani D, McIntyre PG, White K et al. Fatal human rabies caused by European bat Lyssavirus type 2a infection in Scotland. Clin Infect Dis 2003;37:598-601.

3 van Thiel PP, de Bie RM, Eftimov F et al. Fatal human rabies due to Duvenhage virus from a bat in Kenya: failure of treatment with coma-induction, ketamine, and antiviral drugs. PLoS Negl Trop Dis 2009;3:e428.

4 Francis JR, Nourse C, Vaska VL et al. Australian Bat Lyssavirus in a child: the first reported case. Pediatrics 2014;133:e1063-7.

5 Schnell MJ, McGettigan JP, Wirblich C, Papaneri A. The cell biology of rabies virus: using stealth to reach the brain. Nat Rev Microbiol 2010;8:51-61.

6 World Health Organisation. WHO Expert Consultation on Rabies. Second report. World Health Organization technical report series 982. Geneva: WHO, 2013.

7 Gautret P, Blanton J, Dacheux L et al. Rabies in nonhuman primates and potential for transmission to humans: a literature review and examination of selected French national data. PLoS Negl Trop Dis 2014;8:e2863.

8 Vora NM, Basavaraju SV, Feldman KA et al. Raccoon rabies virus variant transmission through solid organ transplantation. JAMA 2013;310:398-407.

9 Warrell DA. The clinical picture of rabies in man. Trans $R$ Soc Trop Med Hyg 1976;70:188-95.

10 Greer DM, Robbins GK, Lijewski V, Gonzalez RG, McGuone D. Case records of the Massachusetts General Hospital. Case 1-2013. A 63-year-old man with paresthesias and difficulty swallowing. N Engl J Med 2013;368:172-80.

11 Jackson AC. Recovery from rabies: a call to arms. J Neurol Sci 2014;339:5-7.

12 de Souza A, Madhusudana SN. Survival from rabies encephalitis. J Neurol Sci 2014;339:8-14.

13 Hattwick MAW, Weis TT, Stechschulte CJ, Baer GM, Gregg MB. Recovery from rabies: a case report. Ann Intern Med 1972;76:931-42.

14 Willoughby Jr RE, Tieves KS, Hoffman GM et al: Survival after treatment of rabies with induction of coma. $N$ Engl J Med 2005;352:2508-14.

15 Jackson AC, Warrell MJ, Rupprecht CE et al. Management of rabies in humans. Clin Infect Dis 2003;36:60-3.

16 Gautret P, Parola P. Rabies in travelers. Curr Infect Dis Rep 2014;16:394.

17 Department of Health. Rabies. In: Immunisation against infectious disease 2006 - The Green Book. London: Department of Health, 2013:329-45. Available online at www.gov.uk/government/uploads/ system/uploads/attachment_data/file/85762/Green-Book-Chapter27-v3_0.pdf [Accessed July 24 2014].

18 Warrell MJ. Current rabies vaccines and prophylaxis schedules: preventing rabies before and after exposure. Travel Med Infect Dis 2012;10:1-15.

19 Manning SE, Rupprecht CE, Fishbein D et al. Human rabies prevention - United States, 2008: recommendations of the Advisory Committee on Immunization Practices. MMWR Recomm Rep 2008;57(RR-3):1-28.

20 Fitzpatrick MC, Hampson K, Cleaveland S et al. Cost-effectiveness of canine vaccination to prevent human rabies in rural Tanzania. Ann Intern Med 21 2014;160:91-100.

Address for correspondence: Dr MJ Warrell, Oxford Vaccine Group, University of Oxford, Centre for Clinical Vaccinology and Tropical Medicine, Churchill Hospital, Old Rd, Headington, Oxford, OX3 7LE, UK.

Email: mary.warrell@ndm.ox.ac.uk 